MATEC Web of Conferences 13, 02013 (2014)

DOI: $10.1051 /$ matecconf/ 20141302013

(C) Owned by the authors, published by EDP Sciences, 2014

\title{
Investigation of Auto-ignition of Several Single Fuels
}

Firmansyah $^{\mathrm{a}}$, A. Rashid. A. Aziz

Universiti Teknologi PETRONAS

Perak darul ridzuan, 31750, Malaysia

\begin{abstract}
HCCI operating principals have been widely investigated yet the uncontrollable combustion of HCCI is the major obstacle in its development. This paper is trying to increase the understanding on the auto-ignition and combustion process of several fuels to be applied in HCCI combustion system. The investigation includes the combustion behavior of 4 fuels, gasoline (RON95), diesel, n-heptane, isooctane, The investigation was done in constant volume chamber with elevated temperature $\left(800^{\circ} \mathrm{C}\right)$. Four lambdas were tested for each fuel namely $0.8,1,1.2$ and 2 . It is found that these fuels can be categorized into two major categories based on combustion characteristics, homogeneous and diffusive combustion. Gasoline and isooctane, homogeneous combustion, shows almost the same behavior where the increase in lambda will increase the combustion delay even though isooctane shows much longer delayed compared to gasoline. While diesel and n-heptane, diffusive combustion, has no ignition delay yet showing different behavior on the later parts of the combustion where diesel effecting $10-90 \%$ combustion stage while n-heptane on 90 $100 \%$.
\end{abstract}

\section{Introduction}

Stringent emissions regulations and significant increase of fuel price highly affecting the growth rate of automotive technology development with the objective of reducing fuel consumption and improving engine efficiency. Controlled autoignition based combustion system such as homogeneous charge compression ignition (HCCI) [1,2], stratified charge combustion ignition (SCCI), and premixed charge compression ignition (PCCI) are the recent engine development with high efficiency, low emissions and fuel consumption.

Fuel type is the most significant parameters in the auto ignition behavior of a mixture [3-8]. Significant number of experiments and simulations in order to improve the understanding of the auto ignition process has been done. Most of the investigations used primary reference fuel (PRF) composition that had similar ignition delay properties as gasoline to get a better understanding of the auto ignition process[9]. The most common PRF are n-heptane and iso-octane. Low temperature reaction is dominant in $\mathrm{n}$-heptane auto ignition showed by cool flame phenomena and the existence of negative temperature coefficient (NTC) [10-11]. While on the other hand, high temperature reaction is dominant in iso-octane autoignition process [12-13].

\footnotetext{
${ }^{a}$ Corresponding author: firmansyah@petronas.com.my
} 
This paper focuses on the autoignition behavior of the commercial fuel (Petronas diesel and gasoline) and the PRF (n-heptane and iso-octane) in a constant volume combustion chamber at elevated temperature.

\section{Methodology}

The study performs extended experimental investigation on the auto ignition behavior of few single fuels. A probe heater is used to increase the temperature inside the combustion chamber. The heater temperature is varied from $400^{\circ} \mathrm{C}$ to $800^{\circ} \mathrm{C}$ in order to get an auto ignition from the mixture. However, preliminary experiment showed that the heater temperature must be set above $800^{\circ} \mathrm{C}$ in order to get a consistent auto ignition from the mixture at combustion chamber pressure equal to 1 bar. Furthermore, oxygen with purity $99.5 \%$ is used as the replacement of air in order to reduce the complexity of the reaction.
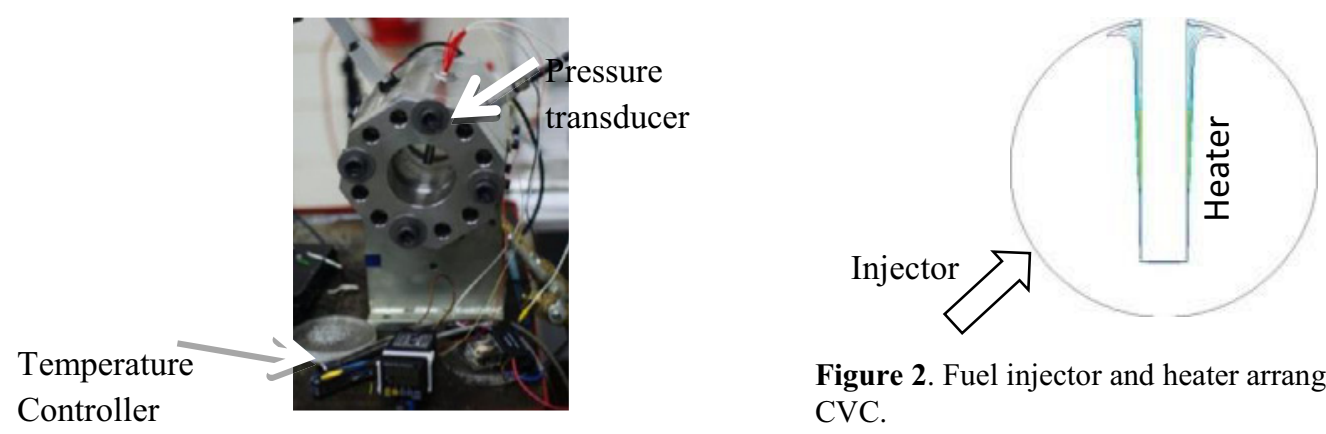

Controller

Figure 2. Fuel injector and heater arrangement in the CVC.

Figure 1. Constant volume chamber.

Table 1. Injector delivery rate for each fuel

\begin{tabular}{|c|c|c|c|}
\hline Fuels & $\begin{array}{c}\text { Injector } \\
\text { delivery rate } \\
(\mathrm{g} / \mathrm{s})-3 \text { bars }\end{array}$ & Fuels & $\begin{array}{c}\text { Injector delivery } \\
\text { rate }(\mathrm{g} / \mathrm{s})-3 \text { bars }\end{array}$ \\
\hline Gasoline & 4.384930188 & N-Heptane & 4.668180598 \\
\hline Diesel & 4.645249846 & Iso-octane & 4.203587459 \\
\hline
\end{tabular}

In the experiment, four fuels are tested namely gasoline, diesel, n-heptane, and octane. The combustion data for these fuels were obtained for various lambdas $(0.8,1,1.2$ and 2$)$ in order to get the effect of lambda to the combustion of the fuel. The injector used is Siemens Deka 4 with 3 bars injection pressure and $4.3 \mathrm{~g} / \mathrm{s}$ delivery rate (manufacturer specification and fuelled with gasoline). Due to density variations of the fuels, calibration process is carried out in the ambient condition for each fuel to measure the actual delivery rate of the injector. The calibration results are shown in Table 1.

Lambda was generated by calculating the stoichiometric reaction between the fuels and oxygen. From the calculation, the required fuel amount for constant volume was determined and was translated to the injector opening by dividing the total fuel required with the injector delivery rate.

During the experiment, 2 stage flushing was applied. The chamber is vacuumed to clear all the left over from the previous combustion process then oxygen is introduced for $15 \mathrm{~s}$ period to make sure there are no air left inside the chamber. The next step is increasing the heater temperature to the set point before the fuel was injected into the chamber. A single trigger point is injecting the fuel $0.4 \mathrm{~s}$ after the pressure data acquisition started. This needs to be done in order to capture the development of the combustion process. 


\section{Results and Discussions}

Combustion behavior results for the four single fuels, gasoline, diesel, iso-octane, and n-heptane, are discussed further in the following section.

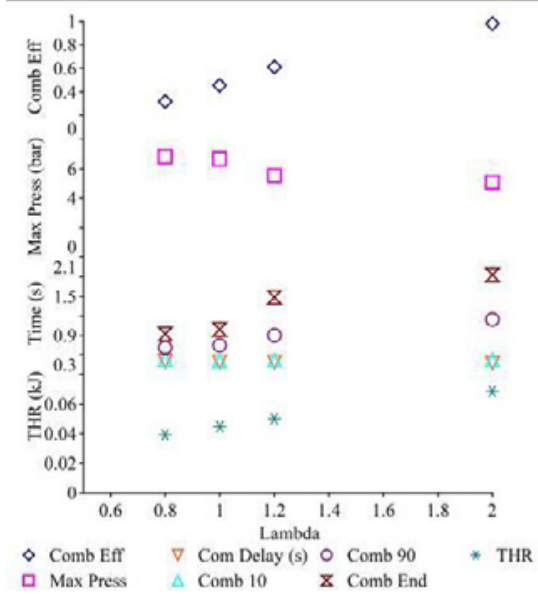

(a) N-heptane

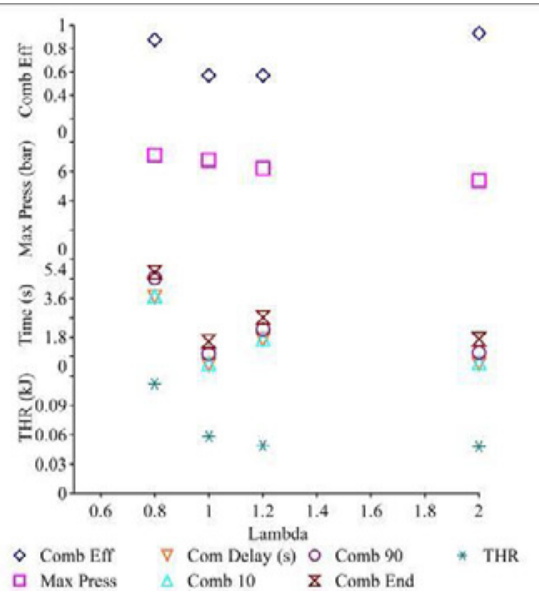

(b) Iso-octane

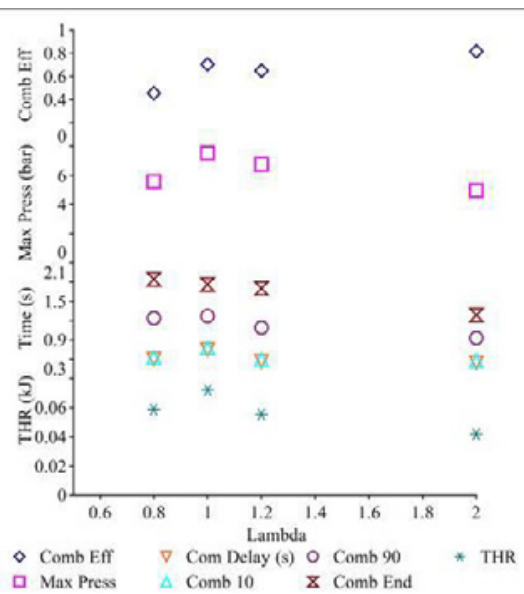

(c) Gasoline

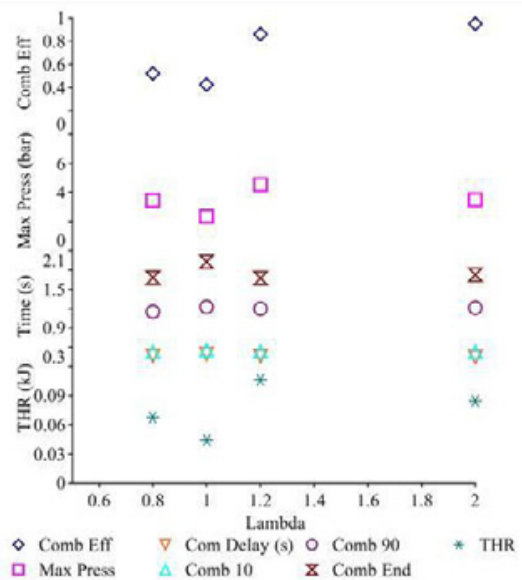

(d) Diesel

Figure 3. Combustion properties of (a) n-heptane, (b) iso-octane, (c) gasoline and (d) diesel

\subsection{N-Heptane}

The ignition timing for every lambda and earlier stage of combustion of $n$-heptane is the same while the last stage of the combustions are different (Figure 3.a). Total heat released, combustion efficiency and combustion duration is increasing with lambda increase. The difference in combustion duration mostly contributed by main combustion stage (10-90\%) and final combustion stage (90$100 \%$ ). This combustion behavior typically related to flame propagation in homogeneous mixture while the short duration of the stages can be related to auto-ignition or stratified combustion. Very short ignition delay of $n$-heptane may also indicates the occurrence of diffusive combustion at the early stage of combustion. 
Faster vaporization rate of n-heptane makes lambda 2 (lean) mixture is easier in achieving homogeneous condition. Initiated with autoignition and continued with homogeneous flame propagation makes higher total heat released, higher combustion efficiency and lower maximum pressure of the lean mixture. Furthermore, the average mixture temperature inside the chamber for lean mixture will be higher compared to the richer one due to heat absorption during vaporization of the droplet.

\subsection{Iso-octane}

Iso-octane combustion shows very long ignition delay compared to the other three fuels as shown in Figure 3.b. The maximum pressure and total heat released is reduced as lambda increase. Furthermore, the delay tends to reduce as lambda increase yet the combustion duration remains the same. This condition is in opposite with previous literature where the leaner mixture showed longer ignition delay [14]. These difference probably due to different experimental setup. In the literature, homogeneous mixture was combusted in constant volume which is different with current setup where the fuel was directly injected to the chamber.

Stratified mixture with large droplet size (due to low injection pressure) creates fuel and temperature stratification in the chamber. In this case, lean mixture will be the one with lesser stratification exist and higher average mixture temperature. This probably the reason of leaner mixture has shorter delay.

It also showed that the ignition delay is dominated by mechanical delay (due to vaporization process) rather than chemical delay. Yet lambda has less significant effect to the combustion duration of iso-octane.

\subsection{Gasoline}

Figure 3.c depicted the properties of gasoline combustion at various lambdas. It is shown that the combustion efficiency trend is increasing with the lambda increase (Figure 3.c). Mechanical delay seems to be the main reason for this behavior. The combustion duration tends to reduce if the lambda increase yet the total heat release of the process are almost the same. Furthermore, the maximum pressure is increase from lambda 0.8 to 1 and decrease for lambda 1 to 2 . These probably shows that the amount of fuels consumed during the combustion process is almost the same for every lambda while longer combustion duration happens due to significant temperature stratification on lower lambda which creates dominated flame propagation process rather than autoignition process in the vicinity of the combustion chamber.

\subsection{Diesel}

Diesel combustion shows different behavior compared to gasoline. Figure 3.d shows that the ignition timing of the diesel-O2 mixtures are the same regardless lambda variation. This phenomenon probably occurs due to the nature of diesel combustion which is diffusion combustion. The diesel fuel directly combust at the time fuel was injected. High soot particles are observed after the diesel experiments which also strongly indicate the diffusion combustion.

As the results of the diesel combustion characteristics, the combustion profile from $0-90 \%$ is the same for every lambda value. The difference is only on the final stage of the combustion which depends on the available fuel left after combustion. 
The combustion properties of diesel also shown that combustion efficiency, combustion duration and combustion delay has less value variation, $0.5-1,1.2-1.25 \mathrm{~s}, 0.04-0.08 \mathrm{~s}$ respectively.

\section{Conclusions}

1. Fuel properties such as autoignition temperature, density, viscosity and fuel amount highly affecting the behavior of fuels in its autoignition combustion.

2. For the diffusive type fuel combustion (Diesel and Heptane), the ignition delay is not affected by lambda yet lambda will show significant effect on the later stage of combustion.

3. While for the homogeneous type of fuel (Gasoline and Octane) combustion, lambda highly affects the ignition delay yet it has less effect on the duration of the combustion.

4. Mechanical delays due to fuel vaporization process are more dominant in the condition where low injection pressure is used and large droplets exist.

\section{References}

1. Onishi. S., Jo. S.H., Shoda. K., Jo. P.D., Kato. S. SAE 790501 (1979)

2. $\quad$ Noguchi. M., Tanaka. Y., Takeuchi. Y. SAE 790840 (1979)

3. Herold. R.E., Krasselt. J.M., Foster. D.E., Ghandhi. J.B., Reuss.D.L., Najt. P.M, SAE 2009-011106 (2009)

4. Yao. M., Zheng. Z, SAE 2007-01-4132 (2007)

5. Berntsson. A.W., Denbratt. I.G. SAE 2007-01-0210 (2007)

6. Kwon. O.S., Jeong. D.W., Lim. O.T., Lida. N. SAE 2009-32-0141/20097141 (2009)

7. Lu.. X.C., Chen.W., Huang. Z, Fuel. 84.1074-1083 (2005)

8. Dec, J.E., Y. Yang, and N. Dronniou. SAE 2011 World Congress.(2011)

9. $\quad$ Yang, Y., et al. SAE 2011 World Congress.(2011).

10. Ranzi, E., Gaffuri, P., Faravelli, T. Comb and Flame. 103. 91-106 (1995)

11. Curran. H. J., Gaffuri. P., Pitz. W. J., Westbrook. C. K. Comb and Flame. 114. 149-177 (1998)

12. Davidson. D.F., Gauthier B.M., Hanson. H.K. Proc Comb Inst. 30. 1175-1182 (2005)

13. Jia. M., Xie. M. A. Fuel. 85. 2593-2604 (2006)

14. Voglsam. S., Winter. F. Chem Eng Jou. 203. 357-369 (2012) 